\title{
Article
}

\section{N-Alkylated Linear Heptamethine Polyenes as Potent Non-Azole Leads against Candida Albicans Fungal Infections}

Lawrence, Clare Louise, Mckenna, Sean Thomas, Vishwapathi, Vinod, Okoh, Adeyi Okoh, Critchley, Megan and Smith, Robert B

Available at http://clok.uclan.ac.uk/33866/

Lawrence, Clare Louise ORCID: 0000-0003-0170-0079, Mckenna, Sean

Thomas, Vishwapathi, Vinod, Okoh, Adeyi Okoh, Critchley, Megan and Smith, Robert B ORCID: 0000-0002-2829-5360 (2020) N-Alkylated Linear Heptamethine Polyenes as Potent Non-Azole Leads against Candida Albicans Fungal Infections. Bioorganic Chemistry, 102 . p. 104070. ISSN 0045-2068

It is advisable to refer to the publisher's version if you intend to cite from the work. http://dx.doi.org/10.1016/j.bioorg.2020.104070

For more information about UCLan's research in this area go to http://www.uclan.ac.uk/researchgroups/ and search for < name of research Group>.

For information about Research generally at UCLan please go to http://www.uclan.ac.uk/research/

All outputs in CLoK are protected by Intellectual Property Rights law, including Copyright law. Copyright, IPR and Moral Rights for the works on this site are retained by the individual authors and/or other copyright owners. Terms and conditions for use of this material are defined in the policies page. 


\title{
$N$-Alkylated Linear Heptamethine Polyenes as Potent Non- Azole Leads against Candida Albicans Fungal Infections
}

Clare L. Lawrence $\mathrm{a}^{\mathrm{*}}$, Adeyi Okoh Okoh ${ }^{\mathrm{b}}$, Vinod Vishwapathi ${ }^{\mathrm{b}}$, Sean T. McKenna ${ }^{\mathrm{b}}$, Megan E. Critchley ${ }^{b}$ and Robert B. Smith ${ }^{b^{*}}$

a UCLan Research Centre for Drug Design and Development, School of Pharmacy and Biomedical Sciences, University of Central Lancashire, Preston, PR1 2HE, UK

b UCLan Research Centre for Smart Materials, University of Central Lancashire, Preston PR1 2HE, UK

Corresponding Authors: cllawrence@uclan.ac.uk \& rbsmith@uclan.ac.uk

\begin{abstract}
In this study, eighteen heptamethine dyes were synthesised and their antifungal activities were evaluated against three clinically relevant yeast species.. The eighteen dyes were placed within classes based on their core subunit i.e. 2,3,3trimethylindolenine (5a-f), 1,1,2-trimethyl-1H-benzo[e]indole (6a-f), or 2methylbenzothiazole ( $7 \mathbf{a}-\mathbf{f})$. The results presented herein imply that the three families of cyanine dyes, in particular compounds 5a-f, show high potential as selective scaffolds to treat $C$. albicans infections. This opens up the opportunity for further optimisation and investigation of this class compounds for potential antifungal treatment.
\end{abstract}

Keywords

Antifungal, Candida Albicans, Cyanine, Hepthamethine, Polyene.

Submitted to

Bioorganic Chemistry

Short Communication 
Immunocompromised patients, such as those with cancer, HIV/AIDs, or recent organ/tissue transplants, are susceptible to infection by opportunistic fungal strains [1]. The morbid effect of these fungal pathogens is having a significant impact on human health worldwide. Estimates of mortality are comparable to that of malaria or tuberculosis [2]. While a limited number of systemic antifungal agents are available to clinicians, resistance to these widely used compounds is increasing globally [3]. This resistance not only has significant direct consequences to human health but also to agriculture, where resistant fungi can have a severe negative impact on food production [4]. Despite this looming threat, the worldwide increase in antifungal resistance is not widely appreciated, particularly when compared with the attention given to the dangers presented by antibiotic resistance [5].

Azoles and their variants (such as imidazoles and triazoles) are particularly important in antifungal chemotherapy. Upon the discovery of their activity in the 1940s, azole compounds revolutionised the treatment of systemic fungal infections, with promising activity against a range of fungal pathogens [6]. Azoles target the cytochrome P450 dependant enzyme lanosterol $14 \alpha$-demthylase CYP 51 . This interrupts the biosynthesis of ergosterol, resulting in disruption to the fungal cell membrane and the build-up of toxic ergosterol precursors that inhibit cell growth [7]. Despite their effectiveness, azoles are not without problems. Resistance to azoles has been reported for various fungi of clinical significance including Candida and Aspergillus species [8, 9]. Moreover, azole resistance has also been observed in infections caused by the normally benign and well-known human commensal organism, Saccharomyces cerevisiae ( $S$. cerevisiae) [10], a budding yeast prevalent in the brewing industry [11]. Additionally, azoles have associated toxicity due to their coordination with haem-groups in mammalian cytochrome $\mathrm{P} 450$ enzymes. Azoles create a considerable clinical challenge in the treatment of immunocompromised patients that may be more vulnerable to the hepatotoxic effects of azole therapy. Ketoconazole, shown in figure 1, was first available as a broad-spectrum antifungal but was later replaced due to adverse gastrointestinal side effects, highlighting another issue associated with this class of compound [12].

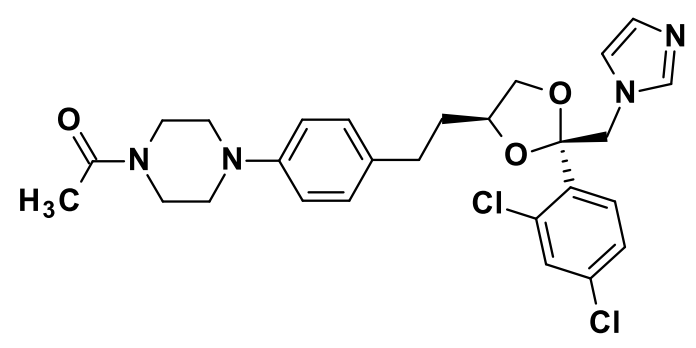

Figure 1. The broad-spectrum antifungal Ketoconazole.

Due to increasing resistance to the limited range of available frontline antifungal drugs, there is a clear and urgent need for novel drug candidates which focus on other classes of antifungal, such as polyenes. Polyene compounds, such as amphotericin B (a systemic antifungal) and nystatin (used orally or topically), are a well-established class of antifungal drug, shown in figure 2. Amphotericin B, in particular, has been in use for over 60 years and resistance remains relatively rare (although reports of 
resistance are increasing) [13]. The antifungal action of polyenes involves the binding of the drug to ergosterol in the fungal cell membrane [6]. This disrupts cell membrane structural stability, leading to porin channel formation and subsequent cellular leakage. This allows the free flow of molecules across the membrane, leading to impaired cellular functions and ultimately cell death. The effective nature of polyene compounds, combined with the relatively limited rate of resistance in medically relevant fungi, suggests that polyenes are an interesting target for novel antifungal development.
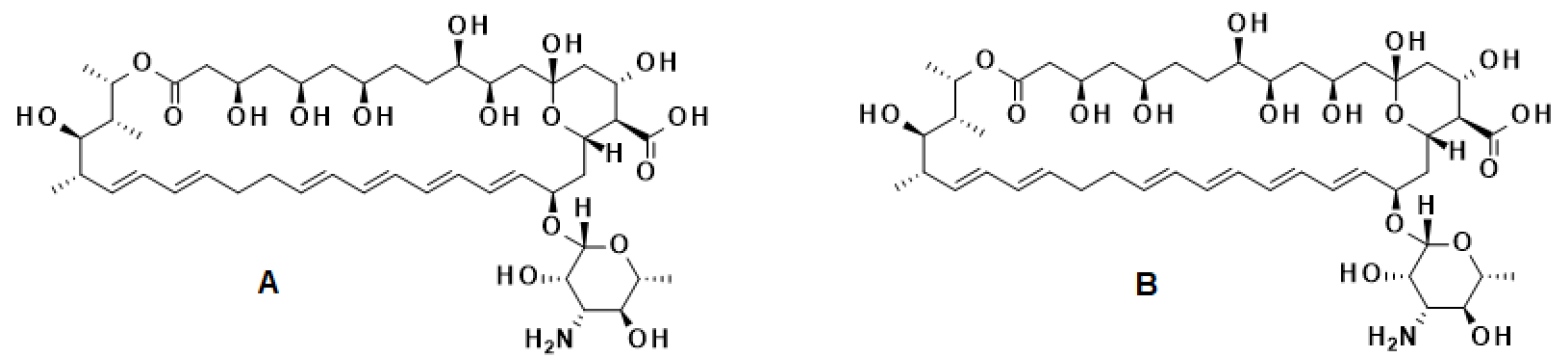

Figure 2. The structures of nystatin (A) and amphotericin B (B)

This work presents a series of $\mathrm{N}$-alkylated linear heptamethine polyenes as potential non-azole leads. This series of synthetic compounds have been tested in vitro against clinically relevant yeast species to establish their effectiveness as antifungal structural leads. Information relating to the synthesis of the compounds within this study can be found within the supporting information.

The synthesis of the linear heptamethine cyanine dyes (5a-f - 7a-f) was straightforward and required no harsh or unusual synthetic methodology. The salts of 2,3,3-trimethylindolenine, 1,1,2-trimethylbenz[e]indole, and 2-methylbenzothiazole were prepared as per literature methods via alkylation with the corresponding alkyl/ benzyl halides or 1,4-butanesultone [14]. The linear cyanine dyes (5a-f - 7a-f) were produced through an in-situ cascade reaction as shown in scheme 1, via the ringopening of $\mathrm{N}$-(2,4-dinitrophenyl)-pyridinium chloride with aniline to produce 5anilino- $N$-phenyl-2,4-pentadienylideniminium chloride (4). This was immediately followed by the direct substitution of the aniline subunit with the $N$-alkylated substituted indolene salt. The reaction takes place under basic conditions at room temperature over a period of 12 hours $[15,16]$. The formation of cyanines was monitored by TLC, but an indication of the dye-forming was seen through an intense colour change (blue/green) after ten minutes of stirring. The crude dyes were purified by column chromatography using silica gel to obtain the reported compounds. For each cyanine dye produced both 1D and 2D NMR experiments were used to confirm thier structure, with other forms of analytical techniques giving further data such mass spectrometry, infrared, UV and melting point. The synthesised compounds (5a-f - 7af) were tested in vitro to determine the minimum inhibitory concentration (MIC) using the micro-dilution method previously reported [17]. 


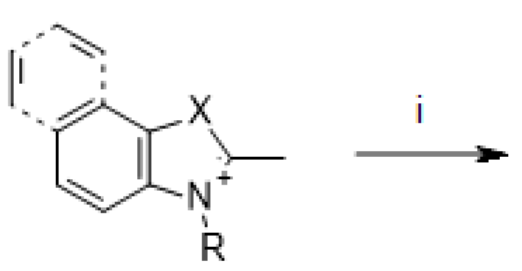

$1(a-f), 2(a-f), 3(a-f)$

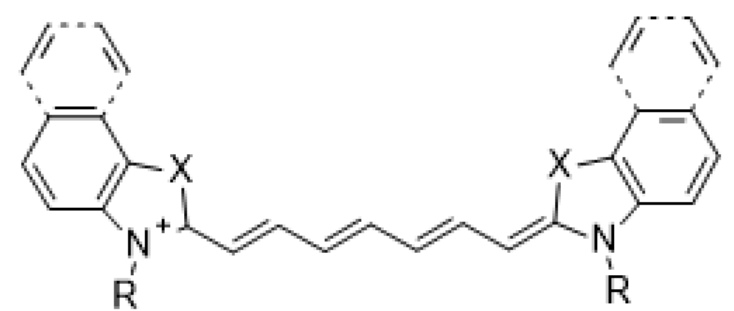

5(a-f), 6(a-f), 7(a-f)

i. 4, Aniline, $\mathrm{NaOAc}$, Ethanol

$$
\begin{aligned}
& \mathrm{R}=\mathrm{a}=\mathrm{Me} \\
& \mathrm{b}=\mathrm{Et} \\
& \mathrm{c}=\mathrm{n}-\mathrm{Pr} \\
& \mathrm{d}=\mathrm{n}-\mathrm{Bu} \\
& \mathrm{e}=\mathrm{Bn} \\
& \mathrm{f}=\mathrm{CH}_{2}\left(\mathrm{CH}_{3}\right)_{3} \mathrm{SO}_{3} \mathrm{H}
\end{aligned}
$$

$$
\begin{aligned}
& \mathrm{X}=\left(\mathrm{CH}_{3}\right)_{2}=2,3,3 \text {-Trimethylindolenine }(1 / 5) \\
& \mathrm{X}=\left(\mathrm{CH}_{3}\right)_{2}=1,1,2 \text {-Trimethyl-1H-benzo[e]indole }(2 / 6) \\
& \mathrm{X}=\mathrm{S}=2 \text {-Methylbenzothiole }(3 / 7)
\end{aligned}
$$

Scheme 1. The synthetic strategy to make the linear cyanine dyes (5a-f $-7 a-f)$.

These were screened against three yeast species, which either demonstrate close homology to several pathogenic fungi or are directly associated with infection. Schizosaccharomyces pombe (S. pombe), a fission yeast, is closely related to Pneumocystis jiroveci which is a fungal infection of the lungs [18]. As noted above, $S$. cerevisiae is becoming an emerging opportunistic pathogen $[19,20]$ and is associated with several conditions such as fungemia [21, 22], peritonitis [23], and meningitis [24]. Finally, Candida albicans (C. albicans) is a diploid fungus well known for opportunistic yeast infections [25], especially oral and genital infections in humans $[26,27]$. These fungal species serve as excellent models to learn more about pathogenic fungi as they share many characteristics with their pathogenic relatives, in particular concerning regulatory features and drug therapy [28-30]. To validate the results, two well-characterised antifungal agents were investigated. Amphotericin B and thiabendazole were employed to compare the efficacy of the compounds presented in this manuscript. Amphotericin B is an extremely potent polyene antifungal and targets sterol in fungal cell membranes. As a positive control, amphotericin B showed high potency against all three species of fungi at $0.061 \mu \mathrm{g} / \mathrm{mL}$ respectively, which is consistent with previously published values [31-32].

Thiabendazole is a known agricultural fungicide and has been used as a positive control when investigating antifungal activity [33]. It has a similar core structure to the molecules presented in this paper. However, thiabendazole has previously shown poor activity against $C$. albicans and $S$. cerevisiae, which may be explained by poor aqueous solubility [34, 35]. This is reinforced by results which showed no growth inhibition when the aforementioned yeast strains were treated with thiabendazole. However, inhibition of $S$. pombe was seen at $62.5 \mu \mathrm{g} / \mathrm{mL}$.

The compounds described have been separated into classes for ease of comparison and are found in Table 1. The compounds have been separated into three classes: class 1 $(\mathbf{5} \mathbf{a}-\mathbf{1 f})$, class $2(\mathbf{6} \mathbf{a}-\mathbf{2 f})$ and class $3(7 \mathbf{a}-\mathbf{3} \mathbf{f})$. 
Table 1. The antifungal data for compounds 5a-f, 6a-f and $7 a-f$.

\begin{tabular}{|c|c|c|c|c|c|c|c|}
\hline \multirow[t]{2}{*}{ Number } & & & & & \multicolumn{3}{|c|}{$\operatorname{MIC}(\mu \mathrm{g} / \mathrm{mL})$} \\
\hline & $\mathbf{R}$ & $\mathbf{X}$ & Yield & $\log P$ & Sp & Sc & $\mathbf{C a}$ \\
\hline $5 \mathbf{a}$ & $\mathrm{CH}_{3}$ & I & $28 \%$ & 3.810 & 1.95 & 62.5 & 7.8 \\
\hline $5 \mathbf{b}$ & $\mathrm{CH}_{2} \mathrm{CH}_{3}$ & I & $49 \%$ & 4.562 & 1.95 & 500 & 15.6 \\
\hline $5 c$ & $\mathrm{CH}_{2} \mathrm{CH}_{2} \mathrm{CH}_{3}$ & $\mathrm{I}$ & $70 \%$ & 5.567 & 1.95 & 125 & 7.8 \\
\hline 5d & $\mathrm{CH}_{2}\left(\mathrm{CH}_{2}\right)_{2} \mathrm{CH}_{3}$ & $\mathrm{I}$ & $33 \%$ & 6.686 & 1.21 & 125 & 5.7 \\
\hline $5 e$ & $\mathrm{CH}_{2} \mathrm{C}_{6} \mathrm{H}_{5}$ & $\mathrm{Br}$ & $22 \%$ & 6.804 & 1.95 & 1000 & 3.9 \\
\hline \multirow[t]{3}{*}{$5 \mathbf{f}$} & $\mathrm{CH}_{2}\left(\mathrm{CH}_{2}\right)_{3} \mathrm{SO}_{3}^{-}$ & - & $74 \%$ & $\begin{array}{c}- \\
1.995\end{array}$ & 10.0 & 703.5 & 10.9 \\
\hline & $\mathrm{R}^{-} \mathrm{X}^{-}$ & & $\mathbf{R}$ & & \multicolumn{3}{|c|}{ MIC $(\mu \mathrm{g} / \mathrm{mL})$} \\
\hline & $\mathbf{R}$ & $\mathbf{X}$ & Yield & $\log P$ & Sp & Sc & $\mathbf{C a}$ \\
\hline $\mathbf{6 a}$ & $\mathrm{CH}_{3}$ & $\mathrm{I}$ & $38 \%$ & 6.129 & 0.007 & 1250 & 6 \\
\hline $6 \mathbf{b}$ & $\mathrm{CH}_{2} \mathrm{CH}_{3}$ & $\mathrm{I}$ & $19 \%$ & 6.881 & 0.03 & 703.5 & 10.9 \\
\hline 6c & $\mathrm{CH}_{2} \mathrm{CH}_{2} \mathrm{CH}_{3}$ & I & $21 \%$ & 7.881 & 0.03 & 625 & 19 \\
\hline 6d & $\mathrm{CH}_{2}\left(\mathrm{CH}_{2}\right)_{2} \mathrm{CH}_{3}$ & I & $29 \%$ & 8.696 & 0.03 & 4750 & 55.6 \\
\hline $6 \mathbf{e}$ & $\mathrm{CH}_{2} \mathrm{C}_{6} \mathrm{H}_{5}$ & $\mathrm{Br}$ & $17 \%$ & 8.753 & 6.74 & $5000^{*}$ & 1250 \\
\hline \multirow[t]{3}{*}{ 6f/ICG } & $\mathrm{CH}_{2}\left(\mathrm{CH}_{2}\right)_{3} \mathrm{SO}_{3}{ }^{-}$ & - & $29 \%$ & 0.323 & 16.6 & $5000^{*}$ & $5000^{*}$ \\
\hline & $\mathrm{R}^{\prime} \mathrm{X}^{-}$ & & $\mathbf{R}$ & & \multicolumn{3}{|c|}{$\operatorname{MIC}(\mu \mathrm{g} / \mathrm{mL})$} \\
\hline & $\mathbf{R}$ & $\mathbf{X}$ & Yield & $\log P$ & Sp & Sc & $\mathbf{C a}$ \\
\hline $7 \mathbf{a}$ & $\mathrm{CH}_{3}$ & I & $79 \%$ & 2.805 & 7.81 & $1000^{*}$ & 3.9 \\
\hline $7 \mathrm{~b}$ & $\mathrm{CH}_{2} \mathrm{CH}_{3}$ & I & $47 \%$ & 3.557 & 7.81 & $1000^{*}$ & 31.3 \\
\hline $7 \mathrm{c}$ & $\mathrm{CH}_{2} \mathrm{CH}_{2} \mathrm{CH}_{3}$ & $\mathrm{I}$ & $69 \%$ & 4.562 & 3.91 & $1000^{*}$ & 31.3 \\
\hline $7 d$ & $\mathrm{CH}_{2}\left(\mathrm{CH}_{2}\right)_{2} \mathrm{CH}_{3}$ & $\mathrm{I}$ & $47 \%$ & 5.681 & 2.93 & $1000^{*}$ & 15.63 \\
\hline $7 e$ & $\mathrm{CH}_{2} \mathrm{C}_{6} \mathrm{H}_{5}$ & $\mathrm{Br}$ & $61 \%$ & 5.994 & 250 & $1000^{*}$ & $1000^{*}$ \\
\hline $7 f$ & $\mathrm{CH}_{2}\left(\mathrm{CH}_{2}\right)_{3} \mathrm{SO}_{3}^{-}$ & - & $47 \%$ & $\begin{array}{c}- \\
3.001\end{array}$ & 15.85 & $5000^{*}$ & $5000^{*}$ \\
\hline
\end{tabular}

MIC's of synthesised compounds tested in S. cerevisiae, S.pombe, and C. albicans. Cells were inoculated at a concentration of $3 \times 10^{4} / \mathrm{ml}$. Culture media tested were in yeast extract broth (YE) for S.pombe and complex growth media (YPD) for S. cerevisiae and C. albicans. Growth of yeast was determined visually after 24 hours incubation at $30{ }^{\circ} \mathrm{C}$. The MIC of the compounds were determined to be the well before yeast growth was first seen. The experiment was repeated twice. Sc - (S. cerevisiae), SP - (S.pombe) and $\mathrm{Ca}-$ (C. albicans). * indicates the maximum concentration tested. LogP calculated using the molinspiration (https://www.molinspiration.com). Compound $\mathbf{6 f}$ is Indocyanine Green but was made in house for this study. 
The key difference of each class is a variation of the "indole type" fragment within the core of each molecule. These changes affect their hydrophilic/hydrophobic character, which seems to play a key role in their activity.

Each class of compound showed excellent activity against $S$. pombe. This is not surprising as $S$. pombe is well known to be relatively sensitive to several antibiotic agents [36] compared to other fungal species. The most hydrophilic of the compounds, the sulphonic acids ( $\mathbf{5} \mathbf{f}, \mathbf{6} \mathbf{f}$ and $\mathbf{7 f}$ ), each showed similar MICs. Compound $\mathbf{7 e}$ showed limited growth inhibitory activity against $S$. pombe with MICs of $250 \mu \mathrm{g} / \mathrm{ml}$. This is highly unexpected and does not align with the other benzyl derivatives, $5 \mathbf{e}$ and $\mathbf{6 e}$, suggesting the sulphur moiety is a contributing factor to poor inhibition activity. This may be due to the increased polarity of the molecule, reducing its interaction with the yeast cell.

Each class of compound showed poor activity against $S$. cerevisiae, with $\mathbf{5 a}$ being the most active at $62.5 \mu \mathrm{g} / \mathrm{mL}$. Class 1 compounds showed limited growth inhibitory activity, with similar MICs seen with compounds $5 \mathbf{a}(62.5 \mu \mathrm{g} / \mathrm{mL}), \mathbf{5 c}(125 \mu \mathrm{g} / \mathrm{mL})$ and $5 \mathbf{d}(125 \mu \mathrm{g} / \mathrm{mL})$, which contain carbon chains of increasing length. However, this was not the case for $\mathbf{5} \mathbf{b}$, where the addition of an $\mathrm{N}$-alkylated ethyl group resulted in a 5 -fold increase in the MIC $(500 \mu \mathrm{g} / \mathrm{mL})$. This result was unexpected as the only difference between compounds $\mathbf{5} \mathbf{a}-\mathbf{d}$, is the increased carbon length of the $\mathrm{R}$ group. This result was consistent across experiments and similar data was observed with $C$. albicans.

The compounds in class 2 follow a similar trend when compared. Against $S$. cerevisiae, little growth inhibition was observed, with MICs exceeding $600 \mu \mathrm{g} / \mathrm{mL}$. This was significantly higher than the measured values for compounds $\mathbf{5 a}-\mathbf{c}$ This indicates the presence of additional phenyl groups from the 1,1,2-trimethyl-1H-benzo[e]indole core moiety has impacted their antifungal activity. Finally, class 3 compounds, with the benzothiazole core, showed no activity in S. cerevisiae at the highest concentration tested $(5000 \mu \mathrm{g} / \mathrm{mL})$ suggesting that the sulphur moiety, as previously described, is a contributing factor to poor activity.

Notably, each class of compound shows increased activity against C.albicans. To expand, the MICs of class 1 compounds were, on average, 10-times lower than those seen in $S$. cerevisiae. For example, compound $5 \mathbf{a}$ in $S$. cerevisiae had an MIC of 62.5 $\mu \mathrm{g} / \mathrm{mL}$ compared to $7.8 \mu \mathrm{g} / \mathrm{mL}$ in C. albicans. Overall, there was little change in the level of growth inhibition between the class 1 compounds, with MICs ranging from 3.9 $-15.6 \mu \mathrm{g} / \mathrm{mL}$. The lowest MIC against C. albicans was observed with compound $\mathbf{5 e}$ at $3.9 \mu \mathrm{g} / \mathrm{mL}$. These results are inconsistent when comparing similar compounds in classes 2 and 3 with "e" and " $\mathrm{f}$ " R groups, showing a significant increase in the MIC compared to other compounds in their class. For example, the MIC for compound $\mathbf{5 e}$ in C.albicans is $3.9 \mu \mathrm{g} / \mathrm{mL}$ compared to $1250 \mu \mathrm{g} / \mathrm{mL}$ in $\mathbf{6 e}$ and $1000 \mu \mathrm{g} / \mathrm{mL}$ in $7 \mathbf{e}$. This may indicate that the increased size of the $N$-alkylated ' $R$ ' group in compound classes 2 and 3 are negatively interacting with the core moiety, resulting in a decrease in the growth inhibitory activity of the compounds.

For class 2 compounds, a similar level of growth inhibition was observed when compared to class 1 for smaller R groups $(\mathbf{5 a}-7 \mathbf{c})$ but, as described above, the MIC 
increased as the $\mathrm{R}$ group size increased. Finally, the compounds in class 3 show a similar trend to the other two classes. Compound $7 \mathbf{a}$ showed the greatest growth inhibition of all tested compounds, with an MIC of $3.9 \mu \mathrm{g} / \mathrm{mL}$. Increasing the length of the linear carbon chain resulted in the MIC increasing 10 fold as shown by $7 \mathbf{b}-\mathbf{c}$. It is interesting to note that compound $\mathbf{7 d}$, with the further increased butyl linear chain, showed a decrease in MIC when compared to $\mathbf{7 c}$. This doesn't reflect the trend observed for the class 2 compounds. However, as the change is approximately 2 -fold, this is likely within experimental error and unlikely to be significant. All three classes of compounds share a polymethine backbone, which suggests this is key to the growth inhibitory activity against C.albicans. In the majority of cases, the addition of the $\mathrm{N}$ alkylated R group appears to interfere with this, increasing the MIC.

To determine the mechanism of action of these compounds, comparisons can be made with key polyene antifungals based on structural similarities. Amphotericin B forms pores within the fungal membrane via mycosamine-mediated interaction with ergosterol. Published work proposes that membrane-bound Amphotericin B assumes two distinct orientations [37]. One is parallel to the membrane bilayer, with the polar head (i.e., mycosamine and the carboxyl group) located at the membrane/water interface and the lactone ring buried within the membrane hydrocarbon core [38-42]. The other is orientated perpendicular to the lipid bilayer with the hydrophobic polyene portion facing the membrane interior and the hydrophilic polyol chain exposed to the aqueous phase [43-45]. Both membrane binding modes might be relevant for amphotericin $\mathrm{B}$ to exert its mechanism of action.

However, natamycin, which also contains a mycosamine group, exerts its effect by binding to ergosterol without forming membrane pores. This results in sterols being unable to perform their normal biological function, resulting in an antifungal effect [46]. The antifungal activity of natamycin is lower than that seen with amphotericin $B$ [47]. Therefore, amphotericin B may have two effects that contribute to its activity, sterol sequestering and membrane permealisation [48].

In comparison with these compounds, the MICs for both amphotericin B (0.03-0.25 $\mu \mathrm{g} / \mathrm{mL})$ [31] and natamycin $(1.13 \mu \mathrm{g} / \mathrm{mL})$ [46], are much lower. The lack of the mycosamine group within our three classes of compounds suggests they are only able to interact with the ergosterol core through favourable hydrophobic interactions with the core polyene moiety of the compounds. This would allow the compounds to sequester ergosterol, similarly to natamycin. Moreover, the cLogP values for class 3 compounds indicate that these are the most hydrophilic and, apart from $7 \mathbf{a}$ in C.albicans, show the least growth inhibition. The increased hydrophilic nature of these molecules may impact these hydrophobic interactions. The class 2 compounds are the most hydrophobic due to the fused phenyl ring and, in C.albicans, the MICs of $6 \mathbf{a}$ and $\mathbf{6 b}$ are lower than that of their corresponding group 1 compound. This suggests that hydrophobicity is a contributing factor to the mechanism of action of these compounds. The reduction in activity seen with $\mathbf{6 c - 6 f}$ may be the result of the introduction of larger $N$-alkylated R groups which may impact their ability to interact with sterols and, therefore, reduce their inhibitory activity. The difference in response of different fungal species to the antifungals might be the result of ergosterol levels 
within the cell, with higher levels of ergosterol being related to increased sensitivity. However, it has been previously reported that there is no significant correlation between MICs and ergosterol content [49].

It has been noted that the macromolecular composition of the cell wall is similar between S. cerevisiae and C. albicans [50]. It should also be noted, although mainly in the membrane, ergosterol is also present in the cell wall [51, 52]. Therefore, it is possible that some of these compounds are binding to the cell wall and the presence of larger substitutions is preventing them from accessing the cell membrane directly. Overall these compounds showed significantly less activity than seen with amphotericin B. Although they may have a similar mode of action via the cell membrane, it is also possible that these compounds may be working via an alternative mechanism. For example, the polyene motif has been demonstrated to produce reactive oxygen species, which can cause oxidative damage to cells [53].

Within this manuscript, we have reported the preparation of three different families of linear heptamethine dyes. Each family was tested against three yeast species including the clinically important $S$. cerevisiae and $C$ albicans. Moreover, their activities were compared against two classical antifungals; amphotericin $\mathrm{B}$ and thiabendazole. The three linear heptamethine families differed only in core sub-unit structure i.e. 2,3,3-trimethylindolenine (5a-f), 1,1,2-trimethyl-1H-benzo[ $e]$ indole (6a-f), or 2-methylbenzothiazole (7a-f). Each of the compound classes shows greater activity when $\mathrm{N}$-alkylated with short-chain hydrocarbons.

It's clear to see compounds $\mathbf{5} \mathbf{a}-\mathbf{f}$ were the most potent, in terms of growth inhibition against $C$ albicans. Further work needs to look at new derivatives of this class of subunit. As such, the results presented here imply that the three families of cyanine dyes, in particular compounds $\mathbf{5} \mathbf{a}-\mathbf{f}$, show high potential as selective scaffolds to treat C. albicans infections.

\section{Notes}

The authors declare no competing financial interest.

\section{Acknowledgement}

We are pleased to acknowledge the financial support from the University of Central Lancashire. 


\section{References}

[1] Nicola, A. M., Albuquerque, P., Paes, H. C., Fernandes, L., Costa, F. F., Kioshima, E. S., Abadio, A. K. R., Bocca, A. L., Felipe, M. S.; Pharmacology and Therapeutics. 2019, 195, 21-38.

[2] Brown, G. D., Denning, D. W., Gow, N. A. R., Levitz, S. M., Netea, M. G., \& White, T. C.; Sci. Transl. Med. 2012, 19, 165-173.

[3] Fisher, M. C., Hawkins, N. J., Sanglard, D., Gurr, S. J.; Science, 2018, 360, 739742.

[4] Savary, S. Ficke, A., Aubertot, J. N., Hollier, C; Food Secur. 2012, 4, 519-537.

[5] Fausto, A., Rodrigues, M. L., Coelho, C.; Frontiers in Microbiology, 2019, 10, art. no. 214.

[6] Maertens, J. A.; Clin. Microbiol. Infect. 2004, 10, 1-10.

[7] Robbins, N., Caplan, T. Cowen, L. E.; Annu. Rev. Microbiol. 2017, 71, 753-775.

[8] Beardsley J., Halliday C. L., Chen S. C., Sorrell T. C.; Future Microbiol. 2018 $13,1175-1191$.

[9] Arikan-Akdagli, S., Ghannoum, M., Meis, J. F.; Journal of Fungi. 2018, 4, 129.

[10] Salonen J. H., Richardson M. D., Gallacher K.; Hosp Infect. 2000, 45, 293-301.

[11] Sampaolesi, S., Gamba, R. R., De Antoni, G. L., León Peláez, Á. M.; LWT, 2019, 113, art. no. 108251.

[12] Kumar, A., Jha, A.; Anticandidal Agents - Elsevier Inc, 2017, 1-83.

[13] O'Shaughnessy, E. M., Lyman, C. A., Walsh, T. J. Antimicrobial Drug Resistance. Infectious Disease. Humana Press. 2009, 295-305.

[14] Tyler, A. R., Okoh, A. O., Lawrence, C. L., Jones, V. C., Moffatt, C., Smith, R. B.; Eur. J. Med. Chem, 2013, 64, 222-227.

[15] Okoh, O. A., Bisby, R. H., Lawrence, C. L., Rolph, C. E., Smith, R. B.; J. Sulfur Chem. 2014, 35, 42-56.

[16] Okoh, O. A., Critchley, M. E., Bisby, R. H., Lawrence, C .L., Wainwright, M., Smith, R. B.; Coloration Technol. 2019, 135, 305-311.

[17] Jalab, M., Critchley, M. E., Taylor, C. M., Lawrence, C. L., Smith, R. B.; Bioorg. Chem, 2019, 91, 103151.

[18] Almeida, J. M. G. C. F., Cissé, O. H., Fonseca, Á., Pagni, M., Hauser, P. M. mBio. 2015, 6, art. no. e02250.

[19] Muñoz, P., Bouza, E., Cuenca-Estrella, M., Eiros, J. M., Pérez, M. J., SánchezSomolinos, M., Rincón, C., Hortal, J., Peláez, T.; Clin Infect Dis. 2oo5, 40, 1625-1634.

[20] Enache-Angoulvant, A., Hennequin, C.; Clin Infect Dis, 2005, 41, 1559-1568.

[21] Fadhel, M., Patel, S., Liu, E., Levitt, M., Asif, A.; Med Mycol Case Rep. 2018, 23, 23-25.

[22] Pillai, U., Devasahayam, J., Kurup, A. N., Lacasse, A.; Saudi J Kidney Dis Transpl. 2014 25, 1266-1269.

[23] Tiballi, R. N., Spiegel, J. E., Zarins, L. T., Kauffman, C. A. Diagn Microbiol Infect Dis. 1995, 23, 135-140.

[24] Brown, J. C. S., Nelson, J., Vandersluis, B., Deshpande, R., Butts, A., Kagan, S., Polacheck, I., Krysan, D. J., Myers, C. L., Madhani, H. D.; Cell. 2014159 11681187.

[25] Vázquez-González, D., Perusquía-Ortiz, A.M., Hundeiker, M., Bonifaz, A.; Journal of the German Society of Dermatology, 2013, 11 381-394.

[26] Terai, H., Ueno, T., Suwa, Y., Omori, M., Yamamoto, K., Kasuya, S.; Jpn Dent Sci Rev. 2018, 54, 52-58. 
[27] Spear, G. T., Reza Zariffard, M., Cohen, M. H., Sha, B. E; J Reprod Immunol. 2008, 78, 76-79.

[28] Hazen, K. C.; Clin. Microbiol. Rev. 1995, 8, 462-478.

[29] Auerbach, D., Arnoldo, A., Bogdan, B., Fetchko, M., Stagljar, I.; Curr. Proteomics. 2005, 2 1-13.

[3o] Qaddouri, B., Guaadaoui, A., Bellirou, A., Hamal, A., Melhaoui, A., Brown, G. W., Bellaoui, M.; Altern. Med. 2011, 1 1-5.

[31] Eksi, F., Gayyurhan, E. D., Balci, I.; The Scientific World Journal, 2o13, art. no. 236903.

[32] Pérez-Cantero, A., Thomson, P., Paredes, K., Guarro, J., Capilla, J.; Revista Iberoamericana de Micologia, 2019, 36, 37-40.

[33] Sui, G., Song, X., Zhang, B., Wang, Y., Liu, R., Guo, H., Wang, J., Chen, Q., Yang, X., Hao, H., Zhou, W.; Eur. J. Med. Chem. 2019, 173, 228-239.

[34] Fai, P. B., Grant, A.; Chemosphere. 2oo9, 74, 1165-1170.

[35] Devereux, M., McCann, M., Shea, M. O., Kelly, R., Egan, D., Deegan, C., Kavanagh, K., McKee, V., Finn, G.; J. Inorg. Biochem. 2004, 98, $1023-1031$.

[36] Thornton, G., Wilkinson, C. R., Toone, W. M., Jones, N.; Genes Cells. 2005, 10 941-951.

[37] Neumann, A., Wieczor, M., Zielinska, J., Baginski, M., Czub, J.; Langmuir, 2016, 32, 3452-3461.

[38] Foglia, F.; Lawrence, M. J.; Demee, B.; Fragneto, G.; Barlow, D. Sci. Rep. 2012, 2, 778 .

[39] Hing, A. W., Schaefer, J., Kobayashi, G. S.; Biochim. Biophys. Acta-Biomembr. 2000, 1463, 323-332.

[40] Lopes, S. Castanho, M. A. R. B.; J. Phys. Chem. B. 2002, 106, 7278-7282.

[41] Kamiński, D. M., Czernel, G., Murphy, B., Runge, B., Magnussen, O. M., Gagoś, M.; Biochim. Biophys. Acta - Biomembr. 2014, 1838, 2947-2953.

[42] Foglia, F. Fragneto, G. Clifton, L. A. Lawrence, M. J. Barlow, D. J. Langmuir 2014, 30, 9147-9156.

[43] Gagos, M., Gabrielska, J., DallaSerra, M., Gruszecki, W. I.; Mol. Membr. Biol. 2005, 22, 433-442.

[44] Matsumori, N., Houdai, T., Murata, M.; J. Org. Chem. 2007, 72, 700-706.

[45] Man, D., Olchawa, R.; J. Liposome Res. 2013, 23, 327-335.

[46] Te Welscher, Y.M., Ten Napel, H.H., Balagué, M.M., Souza, C.M., Riezman, H., De Kruijff, B., Breukink, E.; J. Biol Chem, 2oo8, 283, 6393-6401.

[47] Kotler-Brajtburg, J., Medoff, G., Kobayashi, G. S., Boggs, S., Schlessinger, D., Pandey, C., Rinehart, K. L.; Antimicrob Agents Chemother. 1979, 15, 716-722.

[48] Palacios, D. S., Dailey, I., Siebert, D. M., Wilcock, B. C., Burke, M. D. PNAS, 2011, 108, 6733-6738.

[49] Gomez-Lopez, A., Buitrago, M. J., Rodriguez-Tudela, J. L., Cuenca-Estrella, M.; Revista Iberoamericana de Micologia, 2011, 28, 100-103.

[50] Klis, F. M., de Koster, C. G., Brul, S.; Eukaryotic Cell. 2014, 13, 2-9.

[51] Bianchi D. E., Turian G.; Nature, 1967, 214, 1344-1345.

[52] Gow, N. A. R., Latge, J.-P., Munro, C. A.; Microbiology Spectrum. 2017, 5 art. no. FUNK-0035-2016.

[53] Mesa-Arango, A. C., Trevijano-Contador, N., Román, E., Sánchez-Fresneda, R., Casas, C., Herrero, E., Argüelles, J. C., Pla, J., Cuenca-Estrella, M., Zaragoza, O.; Antimicrob. Agents Chemother. 2014, 58, 6627-6638. 